\title{
Ignition of Solid Propellants by Forced Convection
}

\author{
S. W. CHURCHILL, R. W. KRUGGEL, and J. C. BRIER
}

University of Michigan, Ann Arbor, Michigan

\begin{abstract}
Experimental data are reported for the ignition of single grains of solid propellant in a stream of gas at high temperature. The investigation encompassed gas temperatures from $578^{\circ}$ to $1,070^{\circ} \mathrm{K}$, gas velocities corresponding to free-stream Reynolds numbers from 156 to 624, a complete range of oxygen-nitrogen mixtures, and a few oxygen-carbon dioride mirtures. Pyrocellulose and double-base propellants were tested. The grains were approximately $1 / 8 \mathrm{in}$. in diameter and extended through the gas stream, so that ignition was forced to take place on the cylindrical surface rather than on the end of the grain. The exposure before ignition was measured for a large number of grains. The data can be represented by an equation that is consistent with the known effect of flow rate on convective heat transfer and the known effect of temperature on chemical reaction rates, an indication that both processes are important in ignition.
\end{abstract}

The ignition of a single grain of solid propellant is a complex process involving simultaneous and transient heat transfer, mass transfer, and chemical reactions. The necessary energy may be transferred to the grain by conduction, convection, or radiation. In this investigation ignition was promoted by convective heat transfer from a nonradiating gas stream. Gas temperature, velocity, and composition were varied. Perforated and unperforated cylindrical grains of both single- and double-base propellants were tested. All the grains were approximately $1 / 8$ in. in diameter and were cut about 2 in. long so that the ends projected outside the gas stream and ignition was forced to take place on the cylindrical surface rather than on the edge or end of the grain. The compositions and properties of the propellants tested are given in Table 1.

Previous investigations of the ignition of propellants by a stream of hot gas are limited in number and scope. Crawford, Huggett, and Parr (4) passed single grains of propellant through a Meker burner flame and obtained a linear relationship between the logarithm of ignition time and the reciprocal of the absolute temperature of the flame. Brian and McDowell (1) passed single grains of cordite through a hot-air stream at several rates of flow and obtained $\mathbf{a}$ similar correlation for the effect of temperature. No correlation was presented for the effect of flow rate.

\section{EXPERIMENTAL APPARATUS}

The experimental apparatus consisted principally of a furnace and auxiliaries to provide a uniform stream of hot gas of known dimensions, temperature, velocity, composition, and turbulent intensity; a device to inject a grain of powder into the gas stream transversely; and a device to detect ignition and to measure the time of exposure prior to ignition. The apparatus is shown in Figure 1.

Gas from high-pressure tanks was first passed through rotameters at regulated pressure and then through a heating unit consisting of a 15/8-in. I.D. Zircotube (aluminum oxide) packed with 1/4-in. cylinders and located inside an electric resistance furnace with a cylindrical Globur (silicon carbide) element. The heated gas then passed through a 6 -in.-long by 1 -in. I.D. adiabatic tube packed with 1/4-in. spheres for temperature measurement and finally through two 52-mesh, 0.004-in. wire screens spaced $1 \frac{1}{2}$ in. apart to control the velocity profile and turbulence. The gas thus emerged as a cylindrical stream $1 \mathrm{in}$. in diameter with a velocity profile which deviated less than 5\% from uniformity and an intensity of turbulence of less than $2 \%$.

Radiation from the top of the adiabatic tube was minimized by the use of platinum screens and by wrapping the pellets in the top rows with platinum foil. The adiabatic section was well insulated, and the temperatures of the gas stream and packing were assumed to be equal near the outlet, so that the gas temperature might be measured with a single-wire, butt-welded Chromel-Alumel thermocouple in a porcelain tube extending across the adiabatic tube. Since the temperature of a gas stream issuing from a tube is preserved in a region beyond the exit, the measured temperature was further assumed to be the gas temperature in the test zone. The assumptions involved in the temperature measurement were discussed in detail in a previous paper (2). The thermocouple actuated a continuous-line temperature recorder indicator, which was checked periodically with a precision potentiometer. The furnace temperature was controlled by an off-on switch on the primary side of the step transformer supplying the heating element. The gas temperature, which was not controlled directly, drifted slowly over a range of 1 or $2^{\circ} \mathrm{C}$.

The grains of propellant were held by a spring clip and inserted rapidly into the gas stream 1 in. above the upper screen by a solenoid, as shown in Figure 2. The time of exposure required to produce ignition was measured by a counterchronograph actuated first by the movement of the grain into the gas stream and second by a phototube which responded to radiation from the flame produced upon ignition. The time required for the grain to move from the edge to the center of the gas stream was approximately $9 \mathrm{msec}$. and was included in $\theta$. The grains of propellant were stored at ambient temperatures in vapor-tight containers prior to ignition to minimize drying, etc.

The impurities in the nitrogen totaled less than 0.3 wt. $\%$ and were primarily oxygen. The impurities in the oxygen totaled less than 0.5 wt. $\%$ and were primarily nitrogen and argon. The impurities in the carbon dioxide totaled less than 0.5 wt. $\%$ and were primarily air.

\section{EXPERIMENTAL PROCEDURE}

A run procedure compatible with the instrumentation of the furnace and gassupply system was selected. Tests at 8 series of constant gas temperatures and Reynolds numbers would have been desirable, but the indirect control of the gas temperature and the variation of gas viscosity with temperature made this type of operation impractical. Instead, a given molal flow rate, furnace temperature, and gas composition were established, thus fixing the gas temperature indirectly. All the propellants were tested at the established condition before changing to the next condition. Initial tests did not indicate a significant difference in ignition time for solid grains and longitudinally perforated grains, and tests on the latter were subsequently discontinued.

A random variation in the time of exposure required for ignition was observed, probably owing to real grain-to-grain differences as well as to nonreproducibility in the insertion and detection processes. Therefore, ten ignitions were carried out and the times averaged. If the measured times were particularly inconsistent, a larger number of ignitions were carried out. Including repeat runs, more than 250 experimental conditions and 2,500 ignitions are represented by the correlations.

\section{EXPERIMENTAL RESULTS}

The original data were in the form of average ignition time $\theta$ as a function of the free-stream gas temperature $T_{g}$, the mole fraction of oxygen in the gas $y$, and the molal flow rate $N$ for each propellant; i.e.

$$
\theta=F\left(T_{\theta}, y, N\right)
$$

A typical set of data is given in Table 2. The diameter of the propellant grains was not varied significantly, and the data did not permit sorting out the effect of the different physical properties of the gas. However, on the basis of dimensional analyses, the influence of flow rate was assumed to be character- 


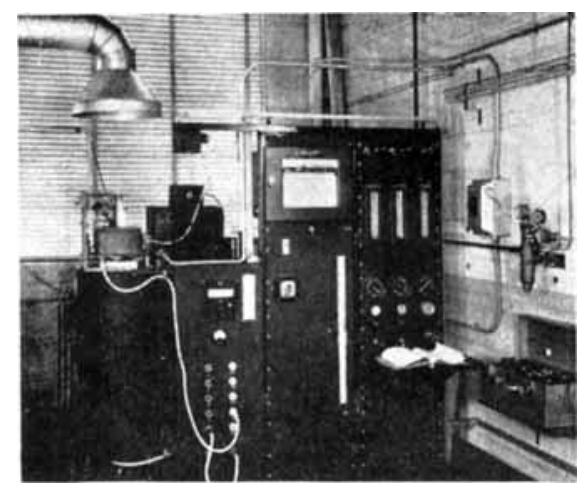

Fig. 1. Experimental apparatus.

ized by the Reynolds number $D u \rho / \mu$, rather than by the mass or linear velocity. The velocity $u$, the density $\rho$, and the viscosity $\mu$ of the gas were arbitrarily evaluated at the free-stream temperature. The desired rate correlation could then be written functionally as

$$
\theta=F\left[y, T_{s},\left(\frac{D u \rho}{\mu}\right)_{s}\right]
$$

It was found by trial and error that the data could be represented by the equation

$$
\frac{1}{\theta}=A\left(\frac{D u \rho}{\mu}\right)_{\theta}^{n} e^{-B / T_{\theta}}
$$

where $n$ is a dimensionless constant and $A$ and $B$ are functions of gas composition and propellant composition. Equation (3) can be rearranged and rewritten in the form

$$
\frac{1}{\theta\left(\frac{D u \rho}{\mu}\right)_{g}^{n}}=I=A e^{-E / R T}
$$

with $I$ interpreted as an ignitibility function, $A$ as a frequency function, and $E$ as an effective energy of activation.

The constants $n, A$, and $E$ were evaluated by repetitive curve fitting. A straight line was drawn through the data for each powder and gas composition when plotted separately, as $\ln \theta$ vs. $1 / T_{\text {。 }}$ for all $(D u \rho / \mu)_{g}$, in order to obtain first approximations for $A$ and $E$. The data for all powders were next plotted together as in $\left(e^{B / R T_{0}} / A \theta\right)$ vs. In $(D u p / \mu)_{0}$ by means of the values of $A$ and $E$ obtained from the first series of plots to obtain a first approximation for $n$. The data for each powder were then plotted separately as $\ln \left[\theta(D u \rho / \mu)_{g^{n}}\right]$ vs. $1 / T_{\mathrm{g}}$ to obtain a second approximation for $A$ and $E$. This process was continued until no improvement in the representation could be noted. The representation proved to be relatively insensitive to values of $n$ in a range from 0.65 to 0.85 , and a value of 0.75 was arbitrarily chosen. The final values of $A$ and $E$ for each powder and gas composition were then determined by least squares and are given in Table 3.

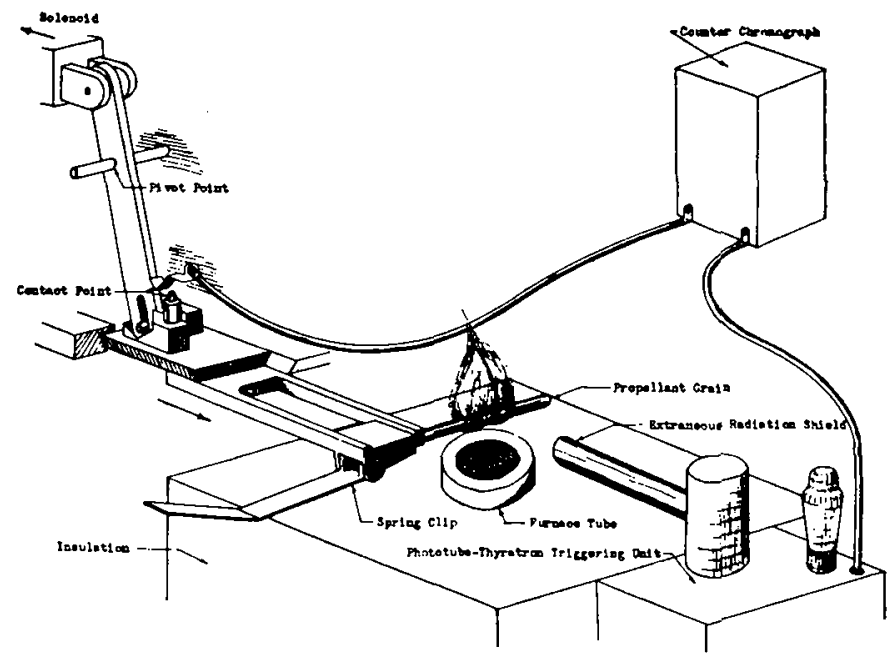

Fig. 2. Apparatus for measurement of ignition time.

The final representation of the data for M-2 type of propellant is illustrated in Figure $3 a, b$, and $c$. Comparable results were obtained for Pyrocellulose and the M-1 type of propellant. All the data are shown in Figure 4, in which $e^{B / R T_{0}} / A \theta$ is plotted vs. $(D u \rho / \mu)_{\sigma}$ on logarithmic coordinates. A line representing the correlation, i.e., through $(D u p / \mu)_{0}=1.0$ and $\left(e^{E / R T} \cdot / A \theta\right)=1.0$ with a slope, $n$, of 0.75 , is shown.

The data obtained for the carbon dioxide-oxygen mixtures were not used in evaluating the constants in the correlations but are included in the final plots for comparison. It is evident that these results do not differ greatly from those obtained with oxygen-nitrogen mixtures.

The effective energy of activation and the frequency function were both found to be dependent on gas composition. Consequently the effect of gas composition can best be illustrated by cross plotting the ignitibility function $I$ for several gas temperatures vs. gas composition as in Figure 5.

\section{QUALITATIVE OBSERVATIONS}

The visible radiation which actuated the phototube and defined ignition was first observed in the gas phase some distance from the powder surface. The flame then developed completely around the grain as a corona. Prior to ignition, etching of the surface of the grain on the underside was visible. At some conditions grains decomposed completely without the appearance of a flame, or a flame first appeared at the fringe of the gas stream and flashed back to the grain. These phenomena were not considered normal ignitions and are not included in the correlation. The decomposition of the propellant grain without visible ignition occurred principally at high flow rates and at low temperatures. Mass transfer is apparently the controlling factor at these conditions.

\section{DISCUSSION OF RESULTS}

If the rate of heat transfer is assumed to be

Table 1. Composition and Properties of Propelinats

Component and property

Nitrocellulose

Nitrogen in nitrocellulose

Dinitrotoluene

Dibutylphthalate

Diphenylamine

Nitroglycerine

Barium nitrate

Potassium nitrate

Ethyl centralite

Graphite

Ether-extractable material

Total volatiles

Moisture (external)

Ash

Average diameter of grain

\begin{tabular}{lll} 
Pyrocellulose & \multicolumn{1}{c}{ M-1 Type } & \multicolumn{1}{c}{ M-2 Type } \\
$99.80 \mathrm{wt} . \%$ & 82.85 wt. $\%$ & $77.84 \mathrm{wt} \%$ \\
12.60 & 13.15 & 13.18 \\
- & 14.67 & \\
- & 1.51 & \\
- & 0.97 & 19.04 \\
- & - & 1.49 \\
- & - & 0.82 \\
- & - & 0.52 \\
$\mathbf{0 . 2 0}$ & - & 0.29 \\
5.27 & & \\
0.25 & 3.33 & 2.52 \\
0.05 & 0.31 & 0.08 \\
& 0.08 & 0.15 \\
$0.3429 \mathrm{~cm}$. & $0.3225 \mathrm{~cm}$. & $0.3429 \mathrm{~cm}$.
\end{tabular}




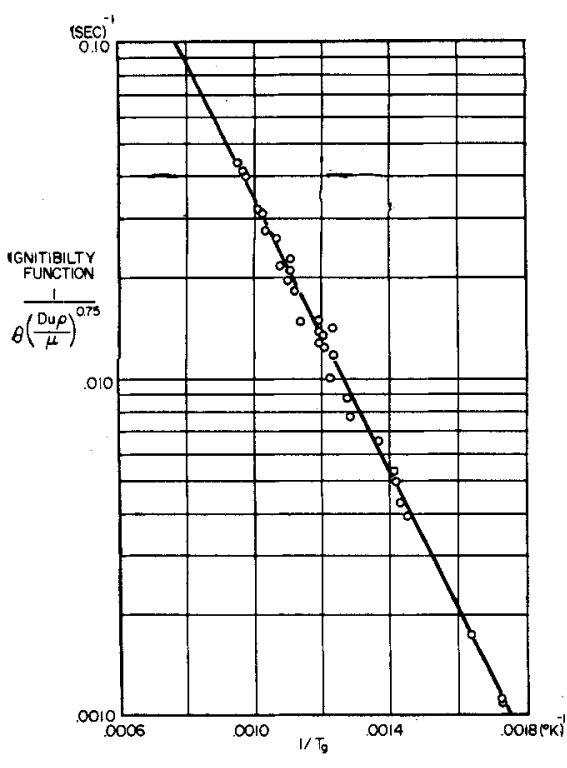

$a$

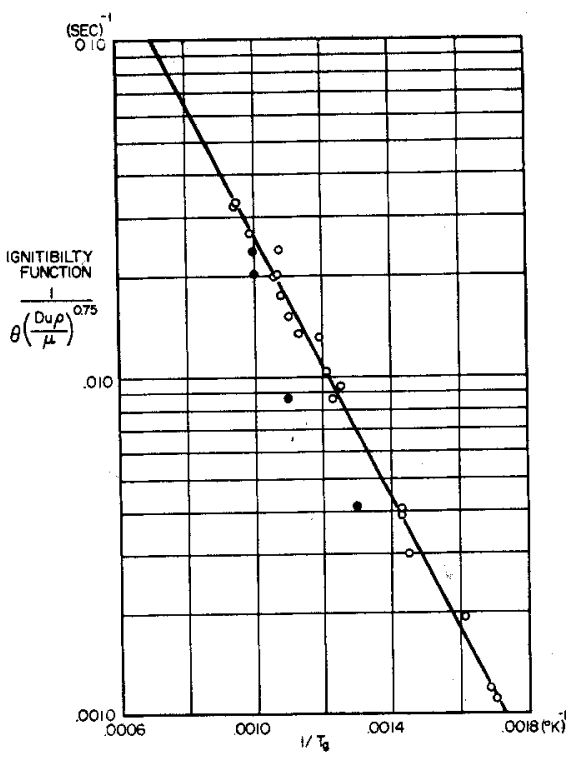

b

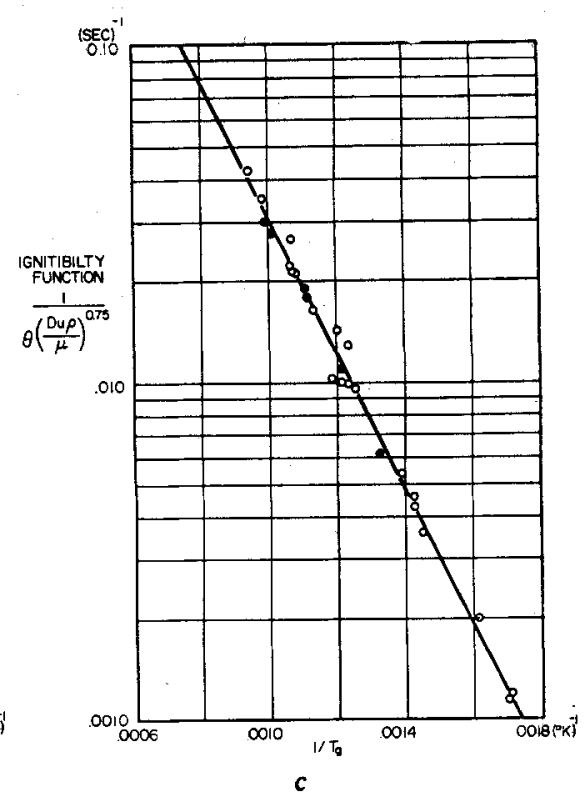

c

Fig. 3. Effect of gas temperature on ignitibility, M-2 type of propellant:

(a) in 100 mole $\% \mathrm{O}_{2}$;

(b) in 20 mole $\% \mathrm{O}_{2}, \mathrm{O} 20$ mole $\% \mathrm{O}_{2}-80$ mole $\% \mathrm{~N}_{2}, 20$ mole $\% \mathrm{O}_{2}-80 \mathrm{~mole} \% \mathrm{CO}_{2}$;

(c) in 50 mole $\% \mathrm{O}_{2}, \bigcirc 50$ mole $\% \mathrm{O}_{2}-50$ mole $\% \mathrm{~N}_{2}, 50$ mole $\% \mathrm{O}_{2}-50$ mole $\% \mathrm{CO}_{2}$.

$$
r=h\left(T_{g}-T_{s}\right)
$$

with $h$ leonstant, the temperature history of the surface of an inert cylinder heated by convection is represented by the equation

$$
\begin{array}{r}
\frac{T_{s}-T_{0}}{T_{g}-T_{0}}=\left(1-e^{-h^{3} \theta / k_{p} c_{p} \rho_{p}}\right) \\
\cdot \operatorname{erfc}\left(h \sqrt{\frac{\theta}{k_{p} c_{p} \rho_{p}}}\right)
\end{array}
$$

\begin{tabular}{|c|c|c|c|c|c|}
\hline $\begin{array}{c}\text { Gas rate, } \\
\text { g.-moles } / \mathrm{min} \text {. }\end{array}$ & $\begin{array}{c}\text { Gas } \\
\text { temperature, } \\
{ }^{\circ} \mathbf{K} .\end{array}$ & $\begin{array}{l}\text { Ignition } \\
\text { time, msec. }\end{array}$ & $\left(\frac{D u \rho}{\mu}\right)_{\rho}$ & $\begin{array}{l}1 / T_{g} \\
\left({ }^{\circ} \mathbf{K} .\right)^{-1}\end{array}$ & $\begin{array}{c}\theta\left(\frac{D u \rho}{\mu}\right)_{0}^{0.76} \\
(\text { sec. })^{-1}\end{array}$ \\
\hline 5.876 & 1,010 & 413 & 411 & 0.000991 & 0.02653 \\
\hline 5.876 & 926 & 608 & 435 & 0.001080 & 0.01727 \\
\hline 5.876 & 814 & 1,145 & 473 & 0.001229 & 0.00862 \\
\hline 5.876 & 689 & 3,049 & 526 & 0.001451 & 0.00299 \\
\hline 5.876 & 588 & 7,650 & 588 & 0.001701 & 0.00110 \\
\hline 5.876 & 883 & 767 & 449 & 0.001133 & 0.01337 \\
\hline 5.876 & 838 & 768 & 465 & 0.001194 & 0.01302 \\
\hline 5.876 & 944 & 535 & 430 & 0.001060 & 0.01980 \\
\hline 4.113 & 1,049 & 447 & 280 & 0.000954 & 0.03268 \\
\hline 4.113 & 1,062 & 456 & 278 & 0.000942 & 0.03215 \\
\hline 4.113 & 933 & 687 & 302 & 0.001072 & 0.02008 \\
\hline 4.113 & 827 & 1,260 & 327 & 0.001210 & 0.01032 \\
\hline 4.113 & 701 & 3,100 & 364 & 0.001428 & 0.00388 \\
\hline 4.113 & 594 & 9,250 & 412 & 0.001684 & 0.00118 \\
\hline 2.351 & 930 & 873 & 174 & 0.001075 & 0.02392 \\
\hline 2.351 & 799 & 2,070 & 192 & 0.001252 & 0.00935 \\
\hline 2.351 & 703 & 4,470 & 209 & 0.001423 & 0.00407 \\
\hline 2.351 & 620 & 8,820 & 227 & 0.001614 & 0.00194 \\
\hline
\end{tabular}

Table 2. Typical Set of Data

M-2-type of propellant; 20 mole $\% \mathrm{O}_{2}-80$ mole $\% \mathrm{~N}_{2}$

Table 3. Frequency Function and Effective Energy of Activation of Propellants

Gas composition, mole $\%$

$100 \% \mathrm{O}_{2}$

$50 \% \mathrm{O}_{2}-50 \% \mathrm{~N}_{2}$

$20 \% \mathrm{O}_{2}-80 \% \mathrm{~N}_{2}$

$100 \% \mathrm{O}_{2}$

$50 \% \mathrm{O}_{2}-50 \% \mathrm{~N}_{2}$

$20 \% \mathrm{O}_{2}-80 \% \mathrm{~N}_{2}$
Pyrocellulose

M-1 Type

M-2 Type

Frequency function $A$, sec. ${ }^{-1}$

$\begin{array}{lll}5.44 & 4.87 & 3.60 \\ 4.80 & 3.07 & 3.25 \\ 2.41 & 1.70 & 2.40\end{array}$

Effective energy of activation $E$, cal./g.-mole

$\begin{array}{lll}9,930 & 9,400 & 9,300 \\ 9,850 & 8,880 & 9,230 \\ \mathbf{9 , 0 2 0} & 8,180 & 8,940\end{array}$

Experimental correlations for the heat transfer coefficient. $h$ have the form

$$
\frac{h D}{k_{g}}=C\left(\frac{D u \rho}{\mu}\right)^{n}
$$

with $n$ approximately 0.5 for the conditions of interest. Hence the time required to reach a given surface temperature would be inversely proportional to $h^{2}$ and in turn to $(D \rho / \mu)_{g}{ }^{2 n}$. The observed influence of Reynolds number on ignition is thus consistent with that predicted on the basis of heat transfer as the controlling mechanism. If mass transfer were controlling, a similar influence of Reynolds number would be predicted.

Rates of chemical reactions are generally proportional to $e^{-E / R T}$. The influence of temperature on ignition is thus superficially consistent with kinetic considerations. However, the values shown in Table 2 for the effective energy of activation for the ignition reactions, 8,182 to $9,935 \mathrm{cal}$./g.-mole, are less than the energy of activation reported for the steady state combustion of similar propellants, 16,000 to $60,000 \mathrm{cal} . / \mathrm{g}$.-mole $(5,6)$. Several explanations are possible: (1) the effect of gas temperature on heat transfer as indicated by Equations (5) and (6) is undoubtedly masked by the exponential effect on the rates of reaction and is, therefore, incorporated in the exponential term and hence modifies the values found for $A$ and $E$; (2) the controlling reactions in ignition may be different from those in steady state combustion and have a lower energy of activation; (3) surface reactions rather than gas-phase reactions may be controlling and the surface temperature or some intermediate rather than the freestream gas temperature may be the 


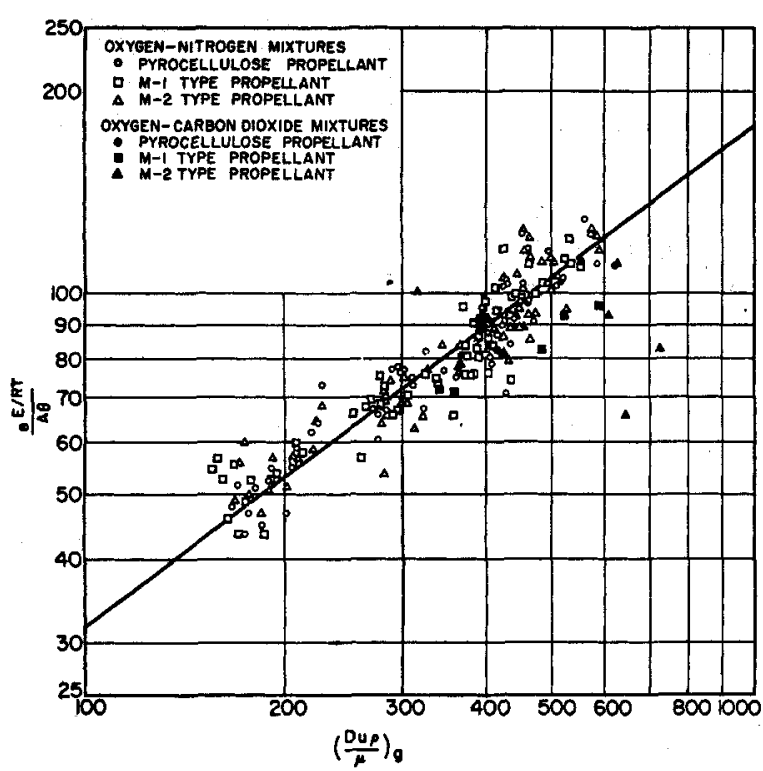

Fig. 4. Effect of flow rate on ignition.

proper temperature in the exponential term. The observed proportionality of the ignition time to both a flow term and an exponential temperature term is in itself somewhat surprising, but it strongly suggests that both convection and rates of reaction are important.

The decrease in ignition time with increasing oxygen content over the entire range of gas compositions, temperatures, and flow rates for all powders suggests that oxidation reactions are controlling. None of the propellants ignited consistently in pure carbon dioxide or nitrogen, and difficulty was encountered with spurious ignitions at the boundary of the gas stream, presumably owing to the penetration of oxygen from the surrounding air. All three propellants tested are oxygen deficient with respect to complete combustion. Almost identical ignition times were observed when nitrogen was replaced with carbon dioxide, an implication that both act as chemically inert gases and hence as a heat and mass transfer media only. Carbon dioxide would presumably demonstrate a chemical effect at extremely high gas temperatures such that the decomposition to oxygen and carbon monoxide was appreciable.

A similar effect of oxygen on the ignition of solid propellants by a detonation wave has been reported by Cook and Olson (3).

The complex variation in composition of the three propellants does not permit specific interpretation of their relative ignitibility in terms of composition. However it can be noted that within the limits investigated the M-1 type of propellant, which contains dinitrotoluene, is most readily ignited. Also, the relative ignitibility of the M-2, which contains nitroglycerine, and of Pyrocellulose, which is almost pure nitrocellulose, shifts with temperature and gas composition.

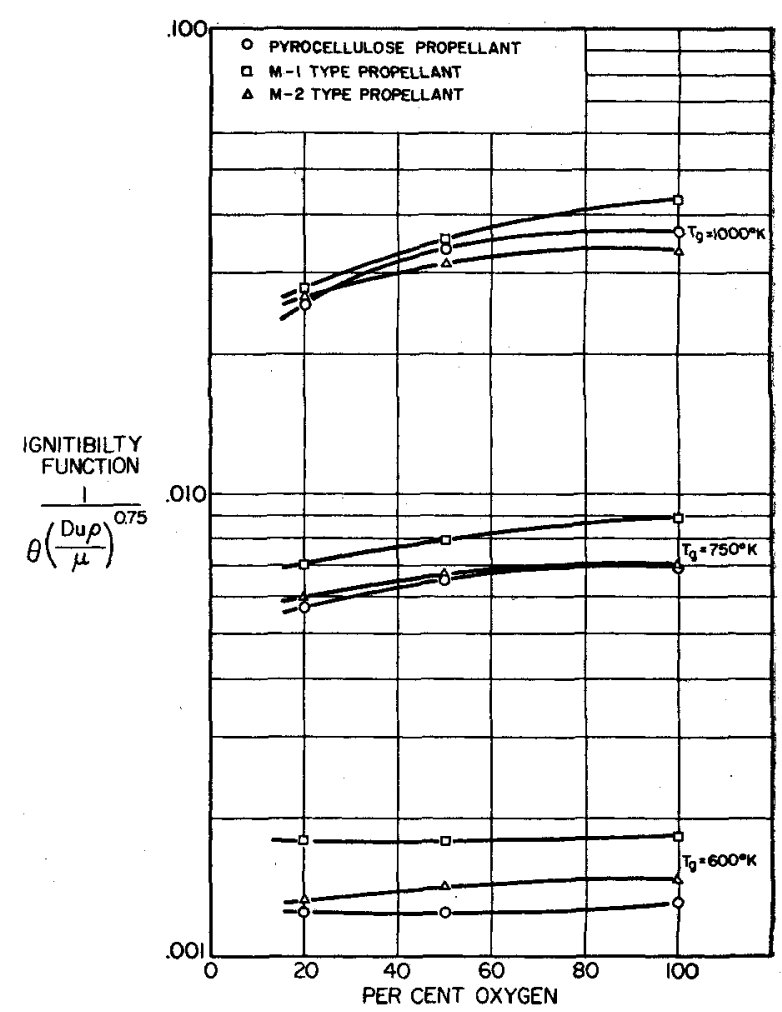

Fig. 5. Effect of gas composition on ignitibility.

The reported temperatures are lower and the ignition times longer than those encountered in weapons, but the excellent correlation found for the effect of temperature suggests extrapolation of the results to higher temperatures with some confidence.

\section{ACKNOWLEDGMENT}

The work was carried out through the Engineering Research Institute of The University of Michigan under contract with the Department of the Navy, Bureau of Ordnance, and the Department of the Army, Office of the Chief of Ordnance. E. D. Blum, D. L. Engibous, S. M. Frank, W. R. Hannenberg, W. P. Hagerty, A. E. Molini, C. M. Thatcher, and H. M. Wolfson assisted in the work.

\section{NOTATION}

$A=$ frequency function, sec. ${ }^{-1}$

$B=$ coefficient in Equation (3), ${ }^{\circ} \mathrm{K}$.

$C=$ coefficient in Equation (7), dimensionless

$c=$ heat capacity, cal. $/$ (g.) $\left({ }^{\circ} \mathrm{C}\right.$. $)$

$D=$ diameter of propellant, cm.

$e \quad=$ base of natural logarithm

$E=$ effective energy of activation, cal./g.-mole

erfe $=$ complementary error function of

$F=$ function of

$h=$ heat transfer coefficient, cal. (sq. cm.) $\left({ }^{\circ} \mathrm{C}\right.$.) (sec.)

$I=$ ignitibility function sec. ${ }^{-1}$

$k=$ thermal conductivity, cal/(sec.) (cm.) $\left({ }^{\circ} \mathrm{C}\right.$.) ln $=$ logarithm to the base $e$

$N=$ gas flow rate, $\mathrm{g} .-\mathrm{mole} / \mathrm{sec}$.

$n=$ exponent of $(D u \rho / \mu)$

$R=$ universal gas constant, cal./(g.mole) $\left({ }^{\circ} \mathrm{K}\right.$.)

$r=$ rate of heat transfer, cal./(sq. cm.) (sec.)

$T=$ temperature, ${ }^{\circ} \mathrm{K}$

$u=$ gas velocity, $\mathrm{cm}$. $/ \mathrm{sec}$.

$y=$ mole fraction oxygen in gas

Greek Letters

$\theta=$ ignition time, sec.

$\mu \quad=$ viscosity, g. $/(\mathrm{sec}).(\mathrm{cm}$.

$\rho=$ density, g. $/$ cc.

\section{Subscripts}

$g \quad=$ free-stream gas

0 = initial

$p=$ propellant

$s \quad=$ surface of propellant

\section{LITERATURE CITED}

1. Brian, R. C., and C. A. MeDowell, Trans. Faraday Soc., 45, 212 (1949).

2. Churchill, S. W., and J, C. Brier, Chem. Eng. Progr., Symposium Ser. No. 17, 51,57 (1955).

3. Cook, M. A., and F. A. Olson, A. I. Ch. E. Journal, 1, 391 (1955).

4. Crawford, B. I.., Jr., C. M. Huggett, and R. G. Parr, Final Report OSRD6374, Appendix No. UM/24 (September, 1954).

5. Rice, O. K., and R. Ginell, J, Phys. \& Colloid Chem., 54, 885 (1950).

6. Robertson, A. J. B., J. Soc. Chem. Ind., 67, 221 (1948). 